\title{
Prosodic accuracy and foreign accent in cultural migrants
}

\author{
Manuela Frontera ${ }^{1}$, Emanuela Paone ${ }^{2}$ \\ ${ }^{1}$ Department of Languages and Education Sciences, University of Calabria, Italy \\ ${ }^{2}$ Department of Humanities, University of Calabria, Italy \\ https://doi.org/10.36505/ExLing-2018/09/0009/000342
}

\begin{abstract}
The present study examines the relationship between language learning motivation and prosodic accuracy in L2 Italian speakers. 4 Romanians and 4 Arabs are selected among cultural migrants living in Italy. Each L1 group includes learners with moderate and high motivational indexes, 2 inexperienced and 2 experienced speakers (indexed by length of residence). Non-native subjects' prosodic accuracy is assessed on 4 declarative sentences in Italian, through acoustic measurements and a perception test. The same sentences are produced by 4 native Italians, acting as a control group. Preliminary results suggest a possible correlation among prosodic accuracy, motivation indexes and LOR levels.

Key words: prosody, foreign accent, motivation, cultural migrants, L2 Italian.
\end{abstract}

\section{Introduction}

Several studies have highlighted that motivation plays an important role in second language acquisition process, strikingly in cultural migrants. Previous studies have claimed that suprasegmental features, as well as segmental features, may lead to the perception of a foreign accent in speech (Flege, 1988; Major, 2001). SLA research has underlined that the development of these aspects represents a huge obstacle for L2 learners, especially in adulthood, even though different investigations suggest that high linguistic motivation levels can play a significant role to achieving native-like pronunciation (Moyer, 1999; Bongaerts et al. 1997).

This study will therefore address the following research questions:

1. Do high motivational levels trigger better prosodic accuracy?

2. How do NN and N speakers' prosodic trends diverge from one another?

3. Is foreign accent still detectable in highly motivated learners?

4. Do other variables, such as the learners' L1 typology and the length of residence have an effect on their prosodic accuracy and consequently on the perceived foreign accent?

ExLing 2018: Proceedings of $9^{\text {th }}$ Tutorial and Research Workshop on Experimental Linguistics, 28-30 August, Paris, Frannce 


\section{Experimental methodology Speakers}

Eight participants, 7 woman and 1 man aged 22-36 years, 4 Romanians and 4 Arabs, are selected among cultural migrants living in Italy. Related sociolinguistic information and indexes of linguistic motivation are provided by a survey from a previous study. Each L1 group includes learners with moderate and high motivational indexes $(2+2), 2$ inexperienced and 2 experienced speakers (indexed by length of residence, less or more than 3 years). Four native Italian speakers are selected as a control group.

\section{Stimuli}

Speech material is elicited through a semi-rigid reading task consisting of 4 declarative sentences in Italian (5 repetitions per speaker). The target utterances are: i) Paolo mette poco zucchero nel caffe; ii) Marco ba molte zie a Piacenza; iii) Mi piace visitare $i$ porti e le starioni; iv) Stiamo perdendo troppe razze di animali.

\section{Task and participants}

77 native Italians are asked to judge the degree of foreign accent perceived in 40 sentences ( 32 by the cultural migrants group, 8 by the control group), using a 3 point Likert-scale (from no foreign accent $=0$ to strong foreign accent $=2$ ).

\section{Analysis}

\section{Prosodic accuracy}

First, values of total duration, silent pauses' duration, $\mathrm{f} 0 \mathrm{max}$ and min are extracted from native and non-native declaratives. Articulation rate (syll/sec excluding pauses) and tonal pitch range are then calculated and statistically compared. Pitch range (that is the difference between the highest and the lowest $\mathrm{fO}$ values in an utterance) is calculated in Hertz and then converted to semitones (ST), since this scale best reflects the intonational equivalence and allows for a normalization across gender (see Nolan 2003).

Data is further analysed through ANOVAs, in order to assess possible correlation among prosodic adequacy (articulation rate and tonal range), motivational indexes, LOR levels and L1s.

\section{Perceptual test}

Mean scores and standard deviations of perceived foreign accent related to every L2 Italian speaker are extracted. Variations in global mean 
scores are tested depending on motivational indexes, levels of LOR, L1s and their interaction.

Finally, the relation between acoustic values and scores of perceived accent is observed.

\section{Results}

The Anova exploring the effect of the speakers (i.e. Romanians, Arabs and Italians) on the articulation rate and tonal pitch range showed it was significant on both the first parametre $[\mathrm{F}(2,45)=17,69, \mathrm{p}=.000]$ and on the tonal pitch range $[\mathrm{F}(2,40)=3,66, \mathrm{p}=.03]$. An unpaired two sample t-test confirmed that there were no significant differences between the Italian and Romanian groups [t(29) $=2,04, \mathrm{p}=.29]$; indeed, articulation rate was quite similar (Rom.: $\mathrm{M}=5,4$ syll./sec, $\mathrm{SD}=1,1$; Ita.: $\mathrm{M}=5$ syll/sec, $\mathrm{SD}=1,2)$. On the contrary, Arabs' articulation rate was much slower $(M=3,4 ; S D=0,7)$, causing a significant difference with respect to Italians' articulation rate, $\mathrm{t}(23)=2,06, \mathrm{p}=.000$. As regards tonal pitch range, native Italians employed a wider range if compared to non nativespeakers' (Ita.: $\mathrm{M}=11,6 \mathrm{ST}$; $\mathrm{SD}=1,9$; Rom.: $\mathrm{M}=9,3 \mathrm{ST}$, $\mathrm{SD}=3,8$; Ar.: $M=9,6 ; S D=2,5)$. Significant differences were found between Arabs and Italians $[\mathrm{t}(20)=2,08, \mathrm{p}=.000]$ but not between Italians and Romanians $[\mathrm{t}(13)=2,1, \mathrm{p}=.2]$.

Among Arab learners significant differences were found between speakers with high and moderate motivational level, with regard to tonal pitch range only, (highly motivated Arabs: $M=10,7$ st; $S D=1 ; t(8)=2,1$; $\mathrm{p}=.06)$. Neither motivational index nor LOR had an effect on articulation rates. Moreover, variability on Romanians' articulation rate and tonal pitch range seems not to be affected by motivational levels or LOR.

As regards the perceptual test, global means of perceived foreign accent set into a 0,36-1,89 range, where the first value is associated to Romanian L1, moderated linguistic motivation and long LOR, while the latter belongs to a Romanian migrant with moderated linguistic motivation and low LOR. Indeed, statistical analyses reveal that there is no a significant interaction among the given variables $(F[1,246]=00,13, p>0.5)$. Nevertheless, L1 and motivational index being equal, a greater LOR is generally associated to a weaker foreign accent, while lower motivational indexes are crucial in determining a stronger perceived foreign accent when L1 and LOR are similar.

Globally speaking, in two out of three cases, a strongly perceived foreign accent goes along with lower articulation rates (NN art.rate $=2,60 ; 3,62$ vs. $\mathrm{N}$ art.rate $=5,07)$ but slight tonal range differences 
(less than 1 semitone). Similarly, a native-like accent responds to almost equal articulation rates respect to the Italian means and does not seem to be intruded upon by greater divergences in the tonal pitch range (more than 1 semitone).

\section{Conclusions}

Results suggest that, as far as native speakers' judgments are concerned, it is not possible to say there is a stable correlation between a higher motivation and a more native-like accent; however, motivation is crucial in determining a weaker perceived foreign accent when L1 and LOR are similar.

Romanian prosodic trends are globally close to native Italian values, regardless their motivational index or LOR, i.e. their prosodic accuracy (articulation rate and tonal pitch range) did not vary according to these variables, but is already quite similar to natives'. On the contrary, high motivational levels trigger better prosodic accuracy in Arabs. Even in this case, different levels of LOR do not determine significant divergences in non-native productions.

\section{References}

Bongaerts, T., Van Summeren, C., Planken, B., Schils, E. 1997. Age and Ultimate Attainment in the Pronunciation of a Foreign Language. Studies in Second Language Acquisition 19, 447-465.

Flege, J. 1988. Factors affecting degree of perceived foreign accent in English sentences. Journal of the Acoustical Society of America 84, 70-79.

Major, R.C. 2001. Foreign accent: The ontogeny and phylogeny of second language phonology. Mahwah, NJ, Lawrence Erlbaum Associates.

Moyer, A. 1999. Ultimate Attainment in L2 Phonology: The critical factors of age, motivation and instruction, Studies in Second Language Acquisition 21(01), 81-108.

Nolan, F. 2003 Intonational equivalence: An experimental evaluation of pitch scales, in Solé, M.J., Recasens, D., Romero, J. (Eds.), Proc. 15th International Congress of Phonetic Sciences, 771-774. 